\title{
Unique Coincidence and Fixed Point Theorem for $g$-Weakly C-Contractive Mappings in Partial Metric Spaces
}

\author{
Saud M. Alsulami \\ Department of Mathematics, King Abdulaziz University, P.O. Box 138381, Jeddah 21323, Saudi Arabia \\ Correspondence should be addressed to Saud M. Alsulami; alsulami@kau.edu.sa
}

Received 10 September 2013; Accepted 13 December 2013; Published 9 January 2014

Academic Editor: Adem Kılıçman

Copyright ( 2014 Saud M. Alsulami. This is an open access article distributed under the Creative Commons Attribution License, which permits unrestricted use, distribution, and reproduction in any medium, provided the original work is properly cited.

We prove that every map satisfying the $g$-weakly C-contractive inequality in partial metric space has a unique coincidence point. Our results generalize several well-known existing results in the literature.

\section{Introduction and Preliminaries}

The Banach contraction principle is the source of metric fixed point theory. This principle had been extended by many authors in different directions (see [1]).

Chatterjea [2] introduced the following contraction which has been named later as C-contraction.

Definition 1 (see [2]). Let $(X, d)$ be a metric space and $f$ : $X \rightarrow X$ a mapping. Then $f$ is called a C-contraction if there exists $k \in[0,1 / 2)$ such that

$$
d(f x, f y) \leq k(d(x, f y)+d(f x, y))
$$

holds for all $x, y \in X$.

Under this kind of contractive inequality, Chatterjea [2] established the following fixed point result.

Theorem 2 (see [2]). Every C-contraction in a complete metric space has a unique fixed point.

As a generalization of C-contractive mapping, Choudhury [3] introduced the concept of weakly C-contractive mapping and proved that every weakly C-contractive mapping in a complete metric space has a unique fixed point.

Definition 3 (see [3]). Let $(X, d)$ be a metric space and $f$ : $X \rightarrow X$ a mapping. Then $f$ is called a weakly $\mathrm{C}$-contractive if $f$ satisfies

$$
\begin{aligned}
d(f x, f y) \leq & \frac{1}{2}(d(x, f y)+d(f x, y)) \\
& -\phi(d(x, f y), d(f x, y))
\end{aligned}
$$

for all $x, y \in X$, where $\phi:[0, \infty) \times[0, \infty) \rightarrow[0, \infty)$ is a continuous mapping such that $\phi(t, s)=0$ if and only if $t=$ $s=0$.

Under this kind of contraction, Choudhury [3] established the following fixed point result.

Theorem 4 (see [3, Theorem 2.1]). Every weakly C-contraction in a complete metric space has a unique fixed point.

Recently, Harjani et al. [4] studied some fixed point results for weakly C-contractive mappings in a complete metric space endowed with a partial order. Moreover, Shatanawi [5] proved some fixed point and coupled fixed point theorems for a nonlinear weakly C-contraction type mapping in metric and ordered metric spaces.

In another aspect, the notion of a partial metric space has been introduced by Matthews [6] in 1994 as a generalization of the usual metric in such a way that each object does not necessarily have to have a zero distance from itself. A motivation behind introducing the concept of a partial metric was to obtain appropriate mathematical models in the theory of computation and, in particular, to give a modified version of the Banach contraction principle (see, e.g., $[7,8])$. Subsequently, several authors studied the problem of existence and uniqueness of a fixed point for mappings satisfying different contractive conditions on partial metric spaces (e.g., [9-13]).

We recall some definitions and properties of partial metric spaces. 
Definition 5. A partial metric on a nonempty set $X$ is a function $p: X \times X \rightarrow \mathbb{R}^{+}$such that for all $x, y, z \in X$,

(p1) $x=y \Leftrightarrow p(x, x)=p(x, y)=p(y, y)$;

(p2) $p(x, x) \leq p(x, y)$;

(p3) $p(x, y)=p(y, x)$;

(p4) $p(x, z) \leq p(x, y)+p(y, z)-p(y, y)$.

A partial metric space is a pair $(X, p)$ such that $X$ is nonempty set and $p$ is a partial metric on $X$.

From the above definition, if $p(x, y)=0$, then $x=y$. But if $x=y, p(x, y)$ may not be 0 in general. A famous example of a partial metric space is the pair $\left(\mathbb{R}^{+}, p\right)$, where $p: \mathbb{R}^{+} \times$ $\mathbb{R}^{+} \rightarrow \mathbb{R}^{+}$is defined as $p(x, y)=\max \{x, y\}$. For some more examples of partial metric spaces, we refer to $[8,12]$.

Each partial metric $p$ on $X$ generates a $T_{0}$ topology $\tau_{p}$ on $X$ which has as a base the family of open $p$-balls: $\left\{B_{p}(x, \epsilon)\right.$ : $x \in X, \epsilon>0\}$, where $B_{p}(x, \epsilon)=\{y \in X: p(x, y)<$ $p(x, x)+\epsilon\}$ for all $x \in X$ and $\epsilon>0$. A sequence $\left\{x_{n}\right\}$ in $X$ converges to a point $x \in X$, with respect to $\tau_{p}$ if and only if $p(x, x)=\lim _{n \rightarrow \infty} p\left(x, x_{n}\right)$. A sequence $\left\{x_{n}\right\}$ in $X$ is called Cauchy sequence if $\lim _{n, m \rightarrow \infty} p\left(x_{n}, x_{m}\right)$ exists and is finite.

Definition $6($ see $[6,13])$. Let $(X, p)$ be a partial metric space. Then,

(i) a sequence $\left\{x_{n}\right\}$ in a partial metric space $(X, p)$ converges to a point $x \in X$ if and only if $p(x, x)=$ $\lim _{n \rightarrow \infty} p\left(x, x_{n}\right)$

(ii) a sequence $\left\{x_{n}\right\}$ in a partial metric space $(X, p)$ is called a Cauchy sequence if there exists (and is finite) $\lim _{n, m \rightarrow \infty} p\left(x_{n}, x_{m}\right)$;

(iii) a partial metric space $(X, p)$ is said to be complete if every Cauchy sequence $\left\{x_{n}\right\}$ in $X$ converges to a point $x \in X$; that is, $p(x, x)=\lim _{n, m \rightarrow \infty} p\left(x_{n}, x_{m}\right)$.

If $p$ is a partial metric on $X$, then the function $p^{s}: X \times$ $X \rightarrow \mathbb{R}^{+}$given by

$$
p^{s}(x, y)=2 p(x, y)-p(x, x)-p(y, y)
$$

is a metric on $X$.

Lemma 7 (see $[6,13])$. Let $(X, p)$ be a partial metric space. Then,

(a) $\left\{x_{n}\right\}$ is a Cauchy sequence in $(X, p)$ if and only if it is a Cauchy sequence in the metric space $\left(X, p^{s}\right)$;

(b) $(X, p)$ is complete if and only if the metric space $\left(X, p^{s}\right)$ is complete. Furthermore, $\lim _{n \rightarrow \infty} p^{s}\left(x_{n}, x\right)=0$ if and only if

$$
p(x, x)=\lim _{n \rightarrow \infty} p\left(x_{n}, x\right)=\lim _{n, m \rightarrow \infty} p\left(x_{n}, x_{m}\right) .
$$

Moreover, Bhaskar and Lakshmikantham [14] presented coupled fixed point theorems for contractions in partially ordered metric spaces. This concept attracted many mathematician and for more related work on coupled fixed and coincidence points results we refer the readers to recent works in $[4,9,10,15-19]$.
Definition 8. Let $f, g: X \rightarrow X$ be two mappings. One says that $x \in X$ is a coincidence point of $f$ and $g$ if $f(x)=g(x)$.

In this paper, we extend the concept of a weakly Ccontractive mapping to the context of partial metric space and define $g$-weakly C-contractive map. Moreover, we prove that every $g$-weakly $\mathrm{C}$-contractive mapping in a complete partial metric space has a unique coincidence point. Our result generalizes several well-known results in the literature.

\section{Unique Coincidence and Fixed Point Theorem}

Definition 9. Let $(X, p)$ be a partial metric space and $g: X \rightarrow$ $X$ a map. Then, the mapping $f: X \rightarrow X$ is said to be $g$ weakly C-contractive if

$$
\begin{aligned}
p(f x, f y) \leq & \frac{1}{2}(p(g x, f y)+p(f x, g y)) \\
& -\phi(p(g x, f y), p(f x, g y))
\end{aligned}
$$

for all $x, y, u, v \in X$, where $\phi:[0, \infty) \times[0, \infty) \rightarrow[0, \infty)$ is a continuous mapping such that $\phi(t, s)=0$ if and only if $t=s=0$.

Now we state and prove our main result.

Theorem 10. Let $(X, p)$ be a complete partial metric space and $f: X \rightarrow X$ a g-weakly C-contraction mapping. Suppose that $f(X) \subset g(X)$. Then, $f$ and $g$ have a unique coincidence point in $X$.

Proof. Let $x_{0} \in X$ be arbitrary point in $X$. Since $f(X) \subset$ $g(X)$, we can construct sequence $\left\{g x_{n}\right\}$ in $X$ as

$$
g x_{n+1}=f x_{n}, \quad \forall n \geq 0 .
$$

Set $\delta_{n}=p\left(g x_{n}, g x_{n+1}\right)$.

If there exists $n \in \mathbb{N}$ such that $\delta_{n}=0$, then by (p1) and (p2) we have $g x_{n}=g x_{n+1}=f x_{n}$. Hence, $f$ and $g$ have a coincidence point in $X$. Now assume that $\delta_{n} \neq 0$ for all $n \geq 0$. Thus by (5), we have

$$
\begin{aligned}
p\left(g x_{n+1}, g x_{n+2}\right)= & p\left(f x_{n}, f x_{n+1}\right) \\
\leq & \frac{1}{2}\left(p\left(g x_{n}, f x_{n+1}\right)+p\left(f x_{n}, g x_{n+1}\right)\right) \\
& -\phi\left(p\left(g x_{n}, f x_{n+1}\right), p\left(f x_{n}, g x_{n+1}\right)\right) \\
= & \frac{1}{2}\left(p\left(g x_{n}, g x_{n+2}\right)+p\left(g x_{n+1}, g x_{n+1}\right)\right) \\
& -\phi\left(p\left(g x_{n}, g x_{n+2}\right), p\left(g x_{n+1}, g x_{n+1}\right)\right) .
\end{aligned}
$$

By property (p4), we have

$$
\begin{aligned}
& p\left(g x_{n}, g x_{n+2}\right)+p\left(g x_{n+1}, g x_{n+1}\right) \\
& \quad \leq p\left(g x_{n}, g x_{n+1}\right)+p\left(g x_{n+1}, g x_{n+2}\right) .
\end{aligned}
$$


Thus from (7), we have

$$
\begin{aligned}
p\left(g x_{n+1}, g x_{n+2}\right) \leq & \frac{1}{2}\left(p\left(g x_{n}, g x_{n+2}\right)+p\left(g x_{n+1}, g x_{n+1}\right)\right) \\
& -\phi\left(p\left(g x_{n}, g x_{n+2}\right), p\left(g x_{n+1}, g x_{n+1}\right)\right) \\
\leq & \frac{1}{2}\left(p\left(g x_{n}, g x_{n+1}\right)+p\left(g x_{n+1}, g x_{n+2}\right)\right) \\
& -\phi\left(p\left(g x_{n}, g x_{n+2}\right), p\left(g x_{n+1}, g x_{n+1}\right)\right) \\
\leq & \max \left\{p\left(g x_{n}, g x_{n+1}\right), p\left(g x_{n+1}, g x_{n+2}\right)\right\} \\
& -\phi\left(p\left(g x_{n}, g x_{n+2}\right), p\left(g x_{n+1}, g x_{n+1}\right)\right) .
\end{aligned}
$$

From (9), we have either $p\left(g x_{n}, g x_{n+2}\right) \neq 0$ or $p\left(g x_{n+1}\right.$, $\left.g x_{n+1}\right) \neq 0$ since $p\left(g x_{n}, g x_{n+1}\right) \neq 0$ for all $n \in \mathbb{N}$.

If

$\max \left\{p\left(g x_{n}, g x_{n+1}\right), p\left(g x_{n+1}, g x_{n+2}\right)\right\}=p\left(g x_{n+1}, g x_{n+2}\right)$,

then since $\phi\left(p\left(g x_{n}, g x_{n+2}\right), p\left(g x_{n+1}, g x_{n+1}\right)\right)>0$ and by (10), we have

$$
\begin{aligned}
p\left(g x_{n+1}, g x_{n+2}\right) \leq & p\left(g x_{n+1}, g x_{n+2}\right) \\
& -\phi\left(p\left(g x_{n}, g x_{n+2}\right), p\left(g x_{n+1}, g x_{n+1}\right)\right) \\
< & p\left(g x_{n+1}, g x_{n+2}\right),
\end{aligned}
$$

which is a contradiction. Thus, we have

$$
\max \left\{p\left(g x_{n}, g x_{n+1}\right), p\left(g x_{n+1}, g x_{n+2}\right)\right\}=p\left(g x_{n}, g x_{n+1}\right)
$$

and therefore

$$
\begin{aligned}
p\left(g x_{n+1}, g x_{n+2}\right) \leq & p\left(g x_{n}, g x_{n+1}\right) \\
& -\phi\left(p\left(g x_{n}, g x_{n+2}\right), p\left(g x_{n+1}, g x_{n+1}\right)\right) \\
\leq & p\left(g x_{n}, g x_{n+1}\right) .
\end{aligned}
$$

By the above inequalities, we have that $\left\{\delta_{n}\right\}=\left\{p\left(g x_{n}, g x_{n+1}\right)\right\}$ is a non increasing sequence of positive real numbers. Therefore, there is some $\delta \geq 0$ such that

$$
\lim _{n \rightarrow \infty} p\left(g x_{n}, g x_{n+1}\right)=\delta .
$$

Then taking the limit as $n \rightarrow \infty$ in (10), we have

$$
\delta \leq \delta-\lim _{n \rightarrow \infty} \phi\left(p\left(g x_{n}, g x_{n+2}\right), p\left(g x_{n+1}, g x_{n+1}\right)\right) \leq \delta .
$$

Then,

$$
\delta-\lim _{n \rightarrow \infty} \phi\left(p\left(g x_{n}, g x_{n+2}\right), p\left(g x_{n+1}, g x_{n+1}\right)\right)=\delta
$$

and therefore

$$
\lim _{n \rightarrow \infty} \phi\left(p\left(g x_{n}, g x_{n+2}\right), p\left(g x_{n+1}, g x_{n+1}\right)\right)=0 .
$$

By continuity of $\phi$, we conclude that

$$
\begin{aligned}
& \lim _{n \rightarrow \infty} p\left(g x_{n}, g x_{n+2}\right)=0, \\
& \lim _{n \rightarrow \infty} p\left(g x_{n+1}, g x_{n+1}\right)=0 .
\end{aligned}
$$

Letting $n \rightarrow \infty$ in (9) and (15), (19), and the continuity of $\phi$, we conclude that $\delta=0$. Thus,

$$
\lim _{n \rightarrow \infty} p\left(g x_{n}, g x_{n+1}\right)=0 .
$$

Next, we will prove that

$$
\lim _{n, m \rightarrow \infty} p\left(g x_{n}, g x_{m}\right)=0
$$

Suppose the contrary; that is,

$$
\lim _{n, m \rightarrow \infty} p\left(g x_{n}, g x_{m}\right) \neq 0 .
$$

Then there exists an $\epsilon>0$ for which we can find subsequences $\left\{g x_{n(k)}\right\},\left\{g x_{m(k)}\right\}$ of $\left\{g x_{n}\right\}$ such that $n(k)$ is the smallest integer for which

$$
n(k)>m(k) \geq k, \quad p\left(g x_{n(k)}, g x_{m(k)}\right) \geq \epsilon .
$$

This means that

$$
p\left(g x_{n(k)-1}, g x_{m(k)}\right)<\epsilon .
$$

From the above two inequalities and (p4), we have

$$
\begin{aligned}
\epsilon \leq & p\left(g x_{n(k)}, g x_{m(k)}\right) \\
\leq & p\left(g x_{n(k)}, g x_{n(k)-1}\right)+p\left(g x_{n(k)-1}, g x_{m(k)}\right) \\
& -p\left(g x_{n(k)-1}, g x_{n(k)-1}\right) \\
\leq & p\left(g x_{n(k)}, g x_{n(k)-1}\right)+p\left(g x_{n(k)-1}, g x_{m(k)}\right) \\
< & \epsilon+p\left(g x_{n(k)}, g x_{n(k)-1}\right) .
\end{aligned}
$$

Letting $k \rightarrow \infty$ and using (20), we get

$$
\lim _{k \rightarrow \infty} p\left(g x_{n(k)}, g x_{m(k)}\right)=\epsilon .
$$


By (p3) and (p4), we have

$$
\begin{aligned}
& p\left(g x_{n(k)}, g x_{m(k)}\right) \\
& \leq p\left(g x_{n(k)}, g x_{n(k)+1}\right)+p\left(g x_{n(k)+1}, g x_{m(k)}\right) \\
&-p\left(g x_{n(k)+1}, g x_{n(k)+1}\right) \\
& \leq p\left(g x_{n(k)}, g x_{n(k)+1}\right)+p\left(g x_{n(k)+1}, g x_{m(k)}\right) \\
& \leq p\left(g x_{n(k)}, g x_{n(k)+1}\right)+p\left(g x_{n(k)+1}, g x_{m(k)+1}\right) \\
&+p\left(g x_{m(k)+1}, g x_{m(k)}\right)-p\left(g x_{m(k)+1}, g x_{m(k)+1}\right) \\
& \leq p\left(g x_{n(k)}, g x_{n(k)+1}\right)+p\left(g x_{n(k)+1}, g x_{m(k)+1}\right) \\
&+p\left(g x_{m(k)+1}, g x_{m(k)}\right) \\
& \leq 2 p\left(g x_{n(k)}, g x_{n(k)+1}\right)+p\left(g x_{n(k)}, g x_{m(k)+1}\right) \\
&+p\left(g x_{m(k)+1}, g x_{m(k)}\right)-p\left(g x_{n(k)}, g x_{n(k)}\right) \\
& \leq 2 p\left(g x_{n(k)}, g x_{n(k)+1}\right)+p\left(g x_{n(k)}, g x_{m(k)+1}\right) \\
&+p\left(g x_{m(k)+1}, g x_{m(k)}\right) \\
& \leq 2 p\left(g x_{n(k)}, g x_{n(k)+1}\right)+p\left(g x_{n(k)}, g x_{m(k)}\right) \\
&+2 p\left(g x_{m(k)+1}, g x_{m(k)}\right)-p\left(g x_{m(k)}, g x_{m(k)}\right) \\
& \leq 2 p\left(g x_{n(k)}, g x_{n(k)+1}\right)+p\left(g x_{n(k)}, g x_{m(k)}\right) \\
&+2 p\left(g x_{m(k)+1}, g x_{m(k)}\right) . \\
&
\end{aligned}
$$

Letting $k \rightarrow+\infty$ in the above inequalities and using (20) and (26), we have

$$
\begin{aligned}
\lim _{k \rightarrow+\infty} p\left(g x_{n(k)}, g x_{m(k)}\right) & =\lim _{k \rightarrow+\infty} p\left(g x_{n(k)+1}, g x_{m(k)}\right) \\
& =\lim _{k \rightarrow+\infty} p\left(g x_{n(k)+1}, g x_{m(k)+1}\right) \\
& =\lim _{k \rightarrow+\infty} p\left(g x_{n(k)}, g x_{m(k)+1}\right)=\epsilon .
\end{aligned}
$$

Therefore, from (5), we have

$$
\begin{aligned}
& p\left(g x_{m(k)+1}, g x_{n(k)+1}\right) \\
&= p\left(f x_{m(k)}, f x_{n(k)}\right) \\
& \leq \frac{1}{2}\left(p\left(g x_{m(k)}, f x_{n(k)}\right)+p\left(f x_{m(k)}, g x_{n(k)}\right)\right) \\
&-\phi\left(p\left(g x_{m(k)}, f x_{n(k)}\right), p\left(f x_{m(k)}, g x_{n(k)}\right)\right) \\
&= \frac{1}{2}\left(p\left(g x_{m(k)}, g x_{n(k)+1}\right)+p\left(g x_{m(k)+1}, g x_{n(k)}\right)\right) \\
&-\phi\left(p\left(g x_{m(k)}, g x_{n(k)+1}\right), p\left(g x_{m(k)+1}, g x_{n(k)}\right)\right) .
\end{aligned}
$$

Letting $k \rightarrow+\infty$ in the above and using (28) and the continuity of $\phi$, we conclude that

$$
\epsilon \leq \epsilon-\phi(\epsilon, \epsilon)<\epsilon
$$

which is a contradiction. Thus, we have

$$
\lim _{n, m \rightarrow+\infty} p\left(g x_{n}, g x_{m}\right)=0 .
$$

Therefore, $\left\{g x_{n}\right\}$ is a Cauchy sequence in the complete partial metric space $(X, p)$.

By Lemma 7, we have that

$$
\lim _{n, m \rightarrow+\infty} p^{s}\left(g x_{n}, g x_{m}\right)=0 .
$$

Thus, $\left\{g x_{n}\right\}$ is a Cauchy sequence in the complete metric space $\left(X, p^{s}\right)$. Hence, by Lemma $7,\left\{g x_{n}\right\}$ is a Cauchy sequence in the complete metric space $(X, p)$. Again, by Lemma 7, there exists $x \in X$ such that

$$
\lim _{n \rightarrow+\infty} p^{s}\left(g x_{n}, g x\right)=0
$$

which implies that

$$
p(g x, g x)=\lim _{n \rightarrow+\infty} p\left(g x_{n}, g x\right)=\lim _{n, m \rightarrow+\infty} p\left(g x_{n}, g x_{m}\right) .
$$

Next, we prove that $\lim _{n \rightarrow+\infty} p\left(f x, g x_{n+1}\right)=p(f x, g x)$. Letting $n \rightarrow+\infty$ in

$$
p\left(f x, g x_{n+1}\right) \leq p(f x, g x)+p\left(g x, g x_{n+1}\right)-p(g x, g x)
$$

we have

$$
\lim _{n \rightarrow+\infty} p\left(f x, g x_{n+1}\right) \leq p(f x, g x) .
$$

Also, letting $n \rightarrow+\infty$ in

$$
\begin{gathered}
p(f x, g x) \leq p\left(f x, g x_{n+1}\right)+p\left(g x_{n+1}, g x\right) \\
-p\left(g x_{n+1}, g x_{n+1}\right),
\end{gathered}
$$

we have

$$
p(f x, g x) \leq \lim _{n \rightarrow+\infty} p\left(f x, g x_{n+1}\right) .
$$

From (36) and (38), we have

$$
\lim _{n \rightarrow+\infty} p\left(f x, g x_{n+1}\right)=p(f x, g x) .
$$

Now, we prove that $f x=g x$. By (5), we have

$$
\begin{aligned}
p\left(f x, g x_{n+1}\right)= & p\left(f x, f x_{n}\right) \\
\leq & \frac{1}{2}\left(p\left(g x, f x_{n}\right)+p\left(f x, g x_{n}\right)\right) \\
& -\phi\left(p\left(g x, f x_{n}\right), p\left(f x, g x_{n}\right)\right) \\
= & \frac{1}{2}\left(p\left(g x, g x_{n+1}\right)+p\left(f x, g x_{n}\right)\right) \\
& -\phi\left(p\left(g x, g x_{n+1}\right), p\left(f x, g x_{n}\right)\right) .
\end{aligned}
$$


Letting $n \rightarrow+\infty$ in the above and using (39) and the continuity of $\phi$, we conclude that

$$
\begin{aligned}
p(f x, g x) & \leq \frac{1}{2} p(f x, g x)-\phi(0, p(f x, g x)) \\
& \leq \frac{1}{2} p(f x, g x) .
\end{aligned}
$$

Hence, $p(f x, g x)=0$. By (p1) and (p2), we have $f x=g x$. Thus, $x$ is a coincidence point of $f$ and $g$.

To prove the uniqueness of the coincidence point of $f$ and $g$, suppose that $y$ is another coincidence point of $f$ and $g$. From (5), we have

$$
\begin{aligned}
p(g x, g y)= & p(f x, f y) \leq \frac{1}{2}(p(x, y)+p(x, y)) \\
& -\phi(p(x, y), p(x, y)) .
\end{aligned}
$$

Therefore, we have $\phi(p(x, y), p(x, y))=0$. Hence, $p(x, y)=0$. By $(\mathrm{p} 1)$ and $(\mathrm{p} 2)$, we have $x=y$.

Thus, $f$ and $g$ have a unique coincidence point.

As an immediate consequence of the above theorem, we have the following fixed point result.

Corollary 11. Let $(X, p)$ be a complete partial metric space and $f: X \rightarrow X$ a weakly $C$-contraction mapping. That is, $T$ satisfies

$$
\begin{aligned}
p(f x, f y) \leq & \frac{1}{2}(p(x, f y)+p(f x, y)) \\
& -\phi(p(x, f y), p(f x, y))
\end{aligned}
$$

for all $x, y \in X$, where $\phi:[0, \infty) \times[0, \infty) \rightarrow[0, \infty)$ is a continuous mapping such that $\phi(t, s)=0$ if and only if $t=s=$ 0 .

Then, there exists a unique $x \in X$ such that $f x=x$.

Corollary 12. Let $(X, p)$ be a complete partial metric space. Suppose that the mapping $f: X \rightarrow X$ satisfies the following contractive condition:

$$
p(f x, f y) \leq k p(f x, y)+l p(x, f y),
$$

for all $x, y, u, v \in X$, where $k, l$ are nonnegative constants with $k+2 l<1$. Then, $f$ has a unique fixed point.

Proof. Take $\phi(t, s)=((1 / 2)-l) t+((1 / 2)-k) s$, where $k$, $l$ are nonnegative constants with $k+2 l<1$.

Corollary 13 (see [10, Corollary 2.7]). Let $(X, p)$ be a complete partial metric space. Suppose that the mapping $f: X \rightarrow X$ satisfies the following contractive condition:

$$
p(f x, f y) \leq \frac{k}{2}(p(f x, y)+p(x, f y)),
$$

for all $x, y \in X$, where $0 \leq k<2 / 3$. Then, $f$ has a unique fixed point.

Proof. Take $\phi(t, s)=((1 / 2)-(k / 2))(t+s)$, where $0 \leq k<$ $2 / 3$.

\section{Conflict of Interests}

The author declares that there is no conflict of interests regarding the publication of this paper.

\section{References}

[1] M. A. Khamsi and W. A. Kirk, An Introduction to Metric Spaces and Fixed Point Theory, Pure and Applied Mathematics, John Wiley \& Sons, New York, NY, USA, 2001.

[2] S. K. Chatterjea, "Fixed-point theorems," Comptes Rendus de l'Académie Bulgare des Sciences, vol. 25, pp. 727-730, 1972.

[3] B. S. Choudhury, "Unique fixed point theorem for weakly C-contractive mappings," Kathmandu University Journal of Science, Engineering and Technology, vol. 5, no. 1, pp. 6-13, 2009.

[4] J. Harjani, B. López, and K. Sadarangani, "Fixed point theorems for weakly C-contractive mappings in ordered metric spaces," Computers and Mathematics with Applications, vol. 61, no. 4, pp. 790-796, 2011.

[5] W. Shatanawi, "Fixed point theorems for nonlinear weakly C-contractive mappings in metric spaces," Mathematical and Computer Modelling, vol. 54, no. 11-12, pp. 2816-2826, 2011.

[6] S. G. Matthews, "Partial metric topology," in Proceedings of the 8th Summer Conference on General Topology and Applications, pp. 183-197, Annals of the New York Academy of Sciences, New York, NY, USA, 1994.

[7] L. Ćirić, B. Samet, H. Aydi, and C. Vetro, "Common fixed points of generalized contractions on partial metric spaces and an application," Applied Mathematics and Computation, vol. 218, no. 6, pp. 2398-2406, 2011.

[8] W. Shatanawi, B. Samet, and M. Abbas, "Coupled fixed point theorems for mixed monotone mappings in ordered partial metric spaces," Mathematical and Computer Modelling, vol. 55, no. 3-4, pp. 680-687, 2012.

[9] S. M. Alsulami, N. Hussain, and A. Alotaibi, "Coupled fixed and coincidence points for monotone operators in partial metric spaces," Fixed Point Theory and Applications, vol. 2012, article 173,2012

[10] H. Aydi, "Some coupled fixed point results on partial metric spaces," International Journal of Mathematics and Mathematical Sciences, vol. 2011, Article ID 647091, 11 pages, 2011.

[11] D. Ilić, V. Pavlović, and V. Rakoević, "Some new extensions of Banach's contraction principle to partial metric space," Applied Mathematics Letters, vol. 24, no. 8, pp. 1326-1330, 2011.

[12] Z. Golubović, Z. Kadelburg, and S. Radenović, "Coupled coincidence points of mappings in ordered partial metric spaces," Abstract and Applied Analysis, vol. 2012, Article ID 192581, 18 pages, 2012.

[13] S. Oltra and O. Valero, "Banach's fixed point theorem for partial metric spaces," Rendiconti dell'Istituto di Matematica dell'Università di Trieste, vol. 36, no. 1-2, pp. 17-26, 2004.

[14] T. G. Bhaskar and V. Lakshmikantham, "Fixed point theorems in partially ordered metric spaces and applications," Nonlinear Analysis, Theory, Methods and Applications, vol. 65, no. 7, pp. 1379-1393, 2006.

[15] A. Alotaibi and S. M. Alsulami, "Coupled coincidence points for monotone operators in partially ordered metric spaces," Fixed Point Theory and Applications, vol. 2011, article 44, 2011.

[16] S. M. Alsulami, "Some coupled coincidence point theorems for a mixed monotone operator in a complete metric space 
endowed with a partial order by using altering distance functions," Fixed Point Theory and Applications, vol. 2013, article 194, 2013.

[17] S. M. Alsulami and A. Alotaibi, "Coupled coincidence point theorems for compatible mappings in partially ordered metric spaces," Bulletin of Mathematical Analysis and Applications, vol. 4, no. 2, pp. 129-138, 2012.

[18] V. Lakshmikantham and L. Ćrić, "Coupled fixed point theorems for nonlinear contractions in partially ordered metric spaces," Nonlinear Analysis, Theory, Methods and Applications, vol. 70, no. 12, pp. 4341-4349, 2009.

[19] N. Hussain, A. Latif, and M. H. Shah, "Coupled and tripled coincidence point results without compatibility," Fixed Point Theory and Applications, vol. 2012, article 77, 2012. 


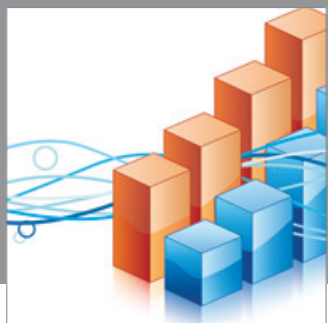

Advances in

Operations Research

mansans

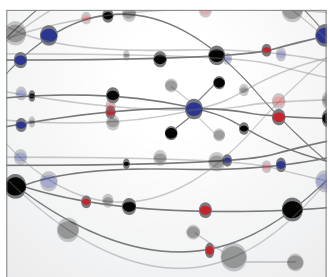

The Scientific World Journal
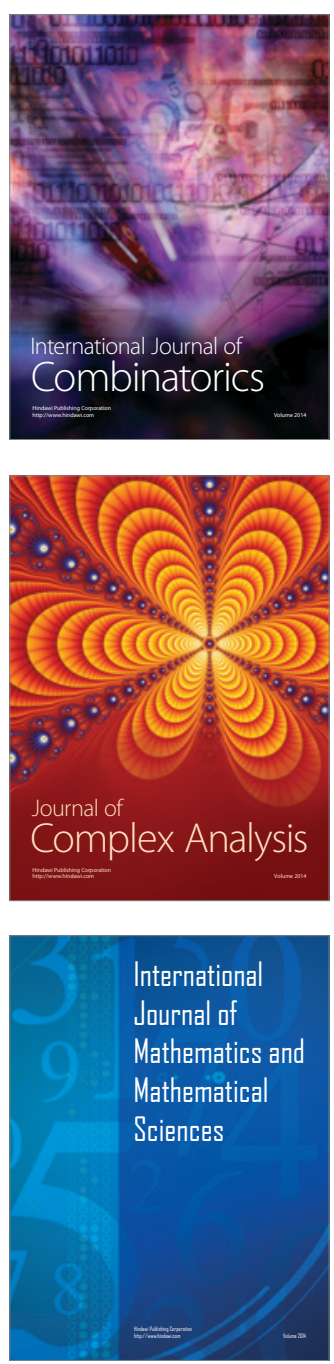
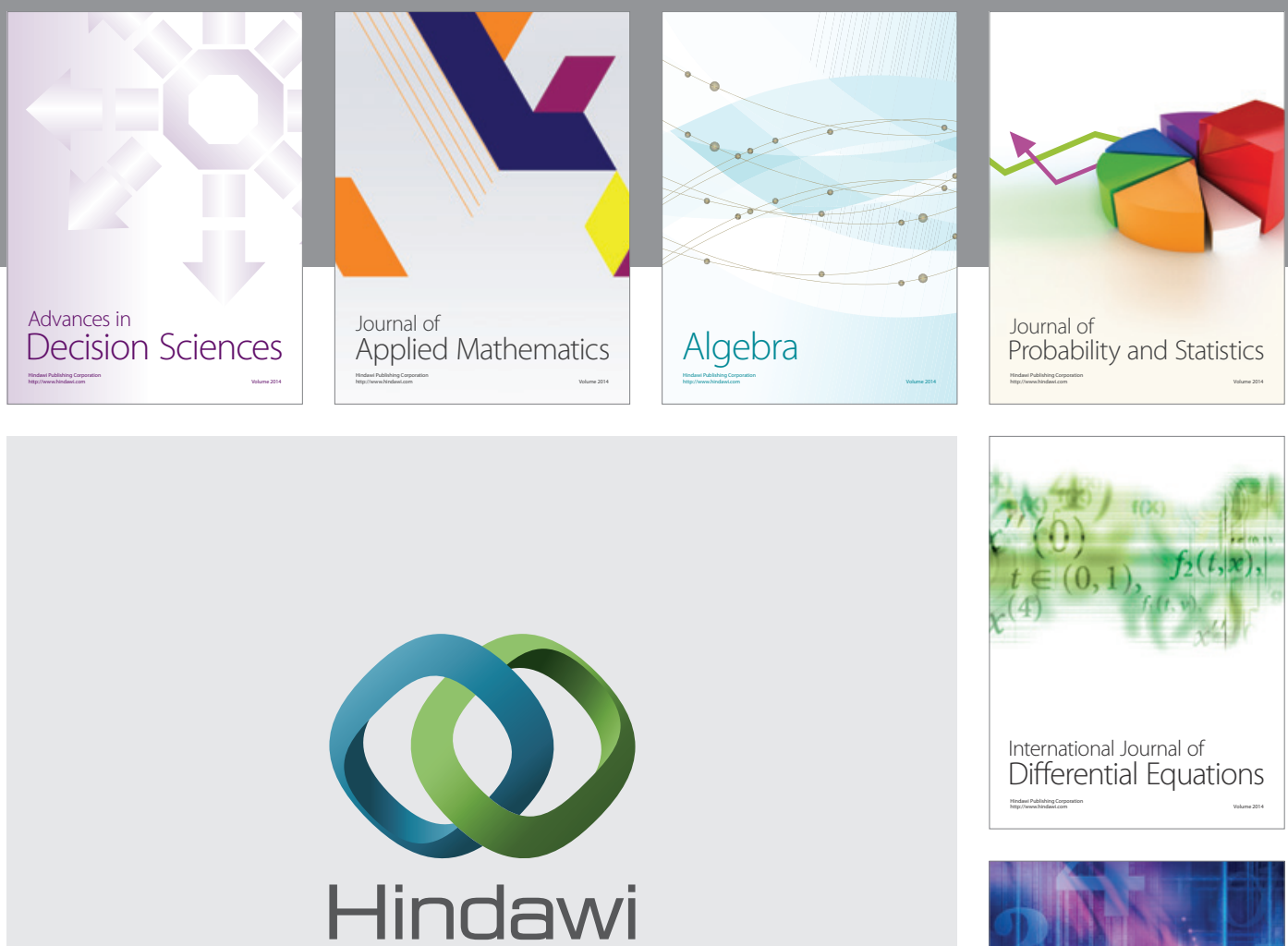

Submit your manuscripts at http://www.hindawi.com
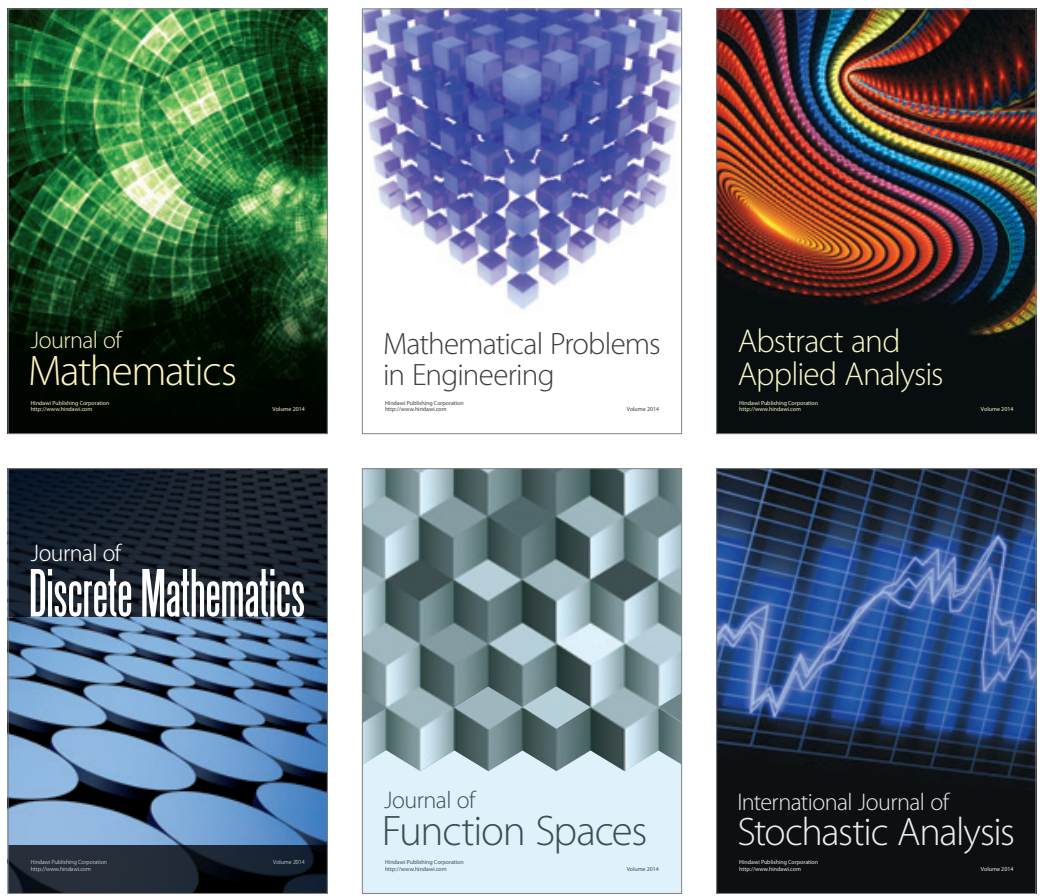

Journal of

Function Spaces

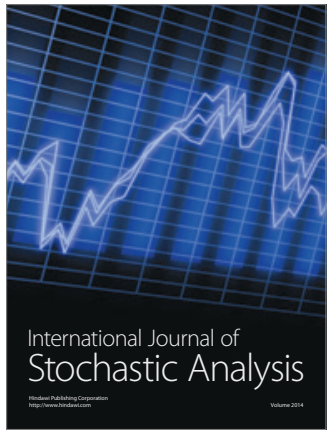

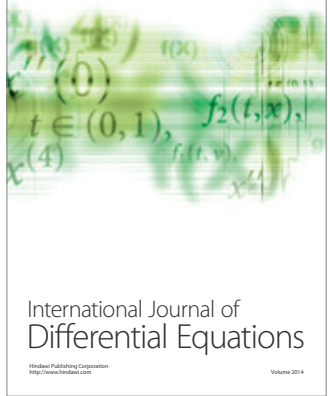
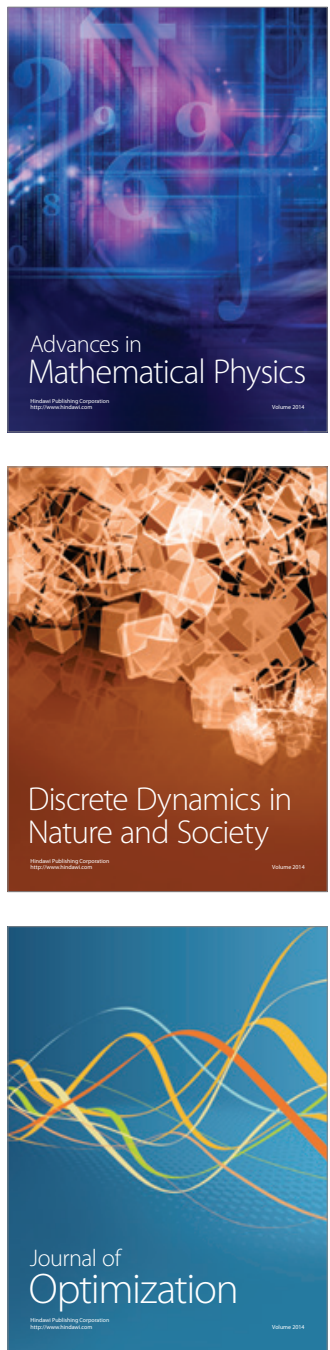